УДК 378.046.4:332.2/7

\title{
НОВЫЙ ПРОФИЛЬ МАГИСТРАТУРЫ ПО НАПРВЛЕНИЮ «ЗЕМЛЕУСТРОЙСТВО И КАДАСТРЫ» В БУРЯТСКОМ \\ ГОСУДАРСТВЕННОМ УНИВЕРСИТЕТЕ («УПРАВЛЕНИЕ, МОНИТОРИНГ И ОХРАНА \\ ЗЕМЕЛЬ ЗАПОВЕДНЫХ ТЕРРИТОРИЙ»)
}

Елаев Эрдэни Николаевич

д.б.н., профессор

Хертуев Валерий Никитич

к.б.н., доцент

Дмитриева Анфиса Валерьевна

к.б.н., доцент

Цыдыпова Марина Владимировна

к.т.н., старший преподаватель

Бурятский государственный университет

имени Доржи Банзарова

Аннотация. Обоснование введения нового профиля магистратуры «Управление, мониторинг и охрана земель заповедных территорий» по направлению «Землеустройство и кадастры» в Бурятском государственном университете им. Д. Банзарова для обеспечения устойчивого развития Байкальского региона. Работа основана на анализе основных профессиональных образовательных программ высшего образования, учебных планов и рабочих программ дисциплин магистратуры по направлению подготовки «Землеустройство и кадастры», апробированных авторами в течение последнего десятилетия на факультете биологии, географии и землепользования Бурятского государственного университета.

Ключевые слова: управление, мониторинг, охрана земель, особо охраняемые природные территории, высшее образование, магистратура, Бурятский государственный университет, региональное развитие. 


\title{
NEW MASTER'S DEGREE PROFILE IN "LAND MANAGEMENT AND CADASTRE” AT BURYAT STATE UNIVERSITY («MANAGEMENT, MONITORING AND CONSERVATION OF PROTECTED AREAS LANDS»)
}

\author{
Erdeni N. Yelayev \\ Valery N. Khertuev \\ Anphisa V. Dmitrieva \\ Marina V. Tsydypova
}

\begin{abstract}
The introduction of a new profile of the master's degree "Management, monitoring and conservation of protected areas lands" in the direction "Land Management and Cadastre" at the Banzarov Buryat State University for ensure sustainable development of the Baikal region to justify. The article is based on the analysis of the main professional educational programs of higher education, academic plans and training programs of master's degree courses in the field of "Land Management and Cadastre", approved by the authors in recent years at the Faculty of Biology, Geography and Land use of the Buryat State University.

Keywords: management, monitoring, land protection, specially protected natural areas, higher education, master's degree, Buryat State University, regional development.
\end{abstract}

Введение. В современных условиях природные ресурсы, включая земельные, испытывают значительную антропогенную нагрузку. Правовое регулирование земель разных категорий (поселений, промышленности, обороны и др.) сводится, в основном, к установлению права собственности и форм природопользования согласно Гражданскому кодексу РФ[1; 2].Однако в отношении земель заповеданных территорий дело обстоит иначе $[3 ; 4 ; 5]$.

Согласно Закону Российской Федерации «Об особо охраняемых природных территориях» № 33-ФЗ от 14 марта 1995 г. «особо охраняемые природные территории (ООПТ - доп. авторов)- участки земли, водной поверхности и воздушного пространства над ними, где располагаются природные комплексы и объекты, которые имеют особое природоохранное, научное, культурное, эстетическое, рекреационное и оздоровительное значение, которые изъяты решениями органов государственной власти полностью или частично из хозяйственного использования и для которых установлен режим особой охраны». 
К землям ООПТ относятся земли: 1) особо охраняемых природных территорий, в т.ч. лечебно-оздоровительных местностей и курортов; 2) природоохранного назначения; 3) рекреационного назначения; 4) историкокультурного назначения; 5) иные особо ценные земли в соответствии с Гражданским кодексом, федеральными законами.

При создании ООПТ первоочередное значение имеет установление правового режима их охраны с целью сохранения типичных и уникальных ландшафтов, поддержания генетического биоразнообразия, охраны объектов живой и неживой природы, консервации объектов культурного наследия. При этом право собственности «уходит» на второй план.

Так, как видно из преамбулы ФЗ, в отношении ООПТ действует режим особой охраны, т.е. эти территории полностью или частично изъяты из хозяйственного оборота, а на приграничных с ними участках создаются охранные зоны с регулируемым режимом земле- и водопользования. Кроме того, владение охраняемыми землями зачастую обременительно, поскольку их использование для получения экономической выгоды невозможно либо осложнено. Земли заповедников и национальных парков признаются общефедеральной, природных парков - региональной собственностью. Заказники (за исключением федеральных), дендропарки и ботанические сады могут находиться как в государственной, так и в региональной собственности. Органы местного самоуправления владеют ООПТ, созданными ими на собственных или изъятых для общественных нужд землях. Земли под памятниками природы могут находиться в муниципальной и (или) частной собственности. Соответственно, порядок отнесения земель к землям ООПТ федерального значения, порядок их использования (управление, контроль, мониторинг и т.д.) и охраны устанавливаются Правительством Российской Федерации на основании федеральных законов. Порядок отнесения земель к землям ООПТ регионального и местного значения, порядок использования и охраны устанавливаются органами государственной власти субъектов Российской Федерации и органами местного самоуправления в соответствии с федеральными законами, законами субъектов Российской Федерации и нормативными правовыми актами органов местного самоуправления.

В связи с вышеизложенным, территориальные конфликты, связанные с землепользованием, традиционным природопользованием, проведением экологического зонирования и планирования заповедных территорий, возникают на разных стадиях, начиная с организации ООПТ и дальнейшем их функционированием [6;7;8]. Поэтому знание основ управления, мониторинга 
и охраны земель, отведенных под ООПТ разного уровня, необходимы самим сотрудникам ООПТ, но, прежде всего, при подготовке будущих специалистов в сфере землепользования и природопользования.

Цель настоящей работы - обосновать введение нового профиля магистратуры «Управление, мониторинг и охрана земель заповедных территорий» по направлению 21.04 .02 «Землеустройство и кадастры» в Бурятском государственном университете им. Д. Банзарова (БГУ) для обеспечения устойчивого развития Байкальского региона.

Материал и метод исследования. Работа основана на анализе основных профессиональных образовательных программ высшего образования (ОПОП ВО), учебных планов и рабочих программ дисциплин (РПД) магистратуры по направлению подготовки 21.04.02 «Землеустройство и кадастры», апробированных авторами в течение последнего десятилетия на факультете биологии, географии и землепользования БГУ [9; 10]. На этой основе разработан и предлагается к реализации новый профиль подготовки будущих магистров - «Управление, мониторинг и охрана земель заповедных территорий».

Полученные результаты и их обсуждение. В БГУ с открытием в 2003 г. кафедры землепользования и земельного кадастра (зав. д.б.н. Б. Б. Ральдин, с 2005 г. к.б.н., проф. В.Н. Хертуев) началась реализация двух лицензированных инженерных специальностей «Земельный и городской кадастры». В 2007 г. в связи с переходом российских ВУЗов на международную (уровневую) систему образования согласно Болонской конвенции был сделан первый набор студентов на направление бакалавриата «Землеустройство и кадастры», в 2009 г. - на направление «Геодезия и дистанционное зондирование». В 2012/2013 гг. на кафедре открылась магистратура по направлению подготовки «Землеустройство и кадастры» [10].

Единственным магистерским профилем по направлению 21.04 .02 «Землеустройство и кадастры» является «Охрана и использование земельных ресурсов». К специальным дисциплинам, которые входят в вариативную часть учебной программы профиля, относятся: Земельный фонд Республики Бурятия (зачет, 1 сем.), Кадастр недвижимости (зачет, 1 семестр), Экологическое право (экзамен, 1 сем.), Методы прикладного анализа природных условий и ресурсов (экзамен, 1 сем.), Управление земельными ресурсами и объектами недвижсиости (зачет, 2 сем.), Правовые основы охраны и рационального использования земельных ресурсов (зачет, 2 сем.), Организация и ведение мониторинга земель (зачет, 2 сем.), Планирование 
мероприятий по эффективному использованию земель (зачет, 2 сем.), Динамика и методы оценки современного состояния земель (зачет, 2 сем.), Эколого-экономическое обоснование оптимизации землепользования по природным зонам (зачет, 3 сем.),Особенности землепользования 6 Байкальском регионе (зачет, 3 сем.), Прогнозирование перспективного использования земель (зачет, 3 сем.), Территориальное планирование и прогнозирование (зачет, 3 сем.), Управление природоохранной деятельностью (экзамен, 3 сем.), Мероприятия по улучшению и охране земель и земельного фонда (экзамен, 3 сем.), Эколого-экономическая экспертиза производственных объектов и территорий (экзамен, 3 сем.), Экономическая оценка экологического ущерба (экзамен, 3 сем.), Экология землепользования (экзамен, 3 сем.), Современные проблемы землеустройства и кадастров (экзамен, 3 сем.). Итого 19 дисциплин.

В качестве примера РПД приведем аннотацию одной из учебных дисциплин:

\section{Преподаватель: к.б.н., доц. А. В. Дмитриева}

\section{Особенности землепользования в Байкальском регионе}

1.Место дисциплины (модуля) в структуре ОПОП. Дисциплина входит в вариативную часть блока Б.1.В.ДВ.05.02. Дисциплины по выбору. К исходным требованиям, необходимым для изучения дисциплины относятся знания, умения и виды деятельности, сформированные в процессе изучения дисциплин: «Земельный фонд Республики Бурятия», «Экология землепользования».

2. Цель освоения дисциплины: теоретическое освоение основных её разделов и методически обоснованное понимание возможности и роли курса при решении задач, связанных с особенностями землепользования в Байкальском регионе.

3. Краткое содержание дисциплины. Противоэрозионная организация территории, ее место в общей системе землеустройства, содержание, методы и принципы составления проектов землеустройства с комплексом противоэрозионных мероприятий.

\section{4. Компетенции, формируемые в результате освоения дисциплины:}

- способность ставить задачи и выбирать методы исследования, интерпретировать и представлять результаты научных исследований в форме отчетов, рефератов, публикаций и публичных выступлений (ПК-13).

5. Планируемые результаты обучения. В результате освоения дисциплины обучающийся должен: 
Знать:

- особой правовой режим охраны и использования земельных ресурсов на Байкальской природной территории;

- основные принципы охраны и использования земельных ресурсов на Байкальской природной территории;

\section{Уметь:}

- использовать правовые основы и принципы экологического зонирования Байкальской природной территории;

\section{Владеть:}

- методами и принципами составления проектов землеустройства с комплексом противоэрозионных мероприятий;

- способностью ориентироваться в специальной литературе.

6. Общая трудоемкость дисциплины.

2 зачетные единицы (72 часа).

7. Форма контроля.

Промежуточная аттестация - зачет (3 семестр).

Учитывая уникальность Байкальского региона, разнообразие категорий ООПТ и особенности землепользования на заповедных территориях в плане управления, мониторинга и охраны земель в интересах устойчивого развития региона $[11 ; 12 ; 13 ; 14 ; 15]$, мы предлагаем открыть новый профиль магистратуры «Управление, мониторинг и охрана земель заповедных территорий». Основные аттестационные показатели его представлены ниже (табл. 1.)

\section{Таблица 1}

\section{Общая характеристика нового профиля обучения}

\begin{tabular}{|c|c|}
\hline Направление / профиль & $\begin{array}{l}\text { Землеустройство и кадастры/ Управление, } \\
\text { мониторинг и охрана земель заповедных } \\
\text { территорий }\end{array}$ \\
\hline Уровень обучения & Магистратура \\
\hline Перечень основных предметов & $\begin{array}{l}\text { Земельный фонд ООПТ и его оценка; } \\
\text { Управление землями заповедных территорий; } \\
\text { Мониторинг заповедных территорий } \\
\text { Защита земель заповедных территорий; } \\
\text { Автоматизированные системы проектирования } \\
\text { и кадастра земель заповедных территорий; } \\
\text { Оценка эффективности землепользования на } \\
\text { ООПт } \\
\text { Планирование и развитие заповедных }\end{array}$ \\
\hline
\end{tabular}




\begin{tabular}{|c|c|}
\hline & $\begin{array}{l}\text { территорий; } \\
\text { Организация проектной деятельности на ООПТ }\end{array}$ \\
\hline $\begin{array}{l}\text { Ориентировочная дата } \\
\text { аккредитации/ } \\
\text { аккредитационный орган }\end{array}$ & $\begin{array}{l}2024 \\
\text { Министерство науки и высшего образования } \\
\text { Российской Федерации }\end{array}$ \\
\hline $\begin{array}{l}\text { Предполагаемая дата начала } \\
\text { осуществления новой } \\
\text { программы }\end{array}$ & $15 / 09 / 2022$ \\
\hline $\begin{array}{l}\text { \% модернизированных } \\
\text { предметов по сравнению с } \\
\text { общим количеством предметов, } \\
\text { включенных в курс }\end{array}$ & $50 \%$ \\
\hline $\begin{array}{l}\text { Количество студентов, которые } \\
\text { будут приняты в первый год/ } \\
\text { второй год }\end{array}$ & 10 \\
\hline $\begin{array}{l}\text { Число преподавателей, } \\
\text { подлежащих обучению }\end{array}$ & 5 \\
\hline Стажировка / размещение & 5 \\
\hline $\begin{array}{l}\text { Список оборудования, которое } \\
\text { необходимо приобрести для } \\
\text { этого курса }\end{array}$ & $\begin{array}{l}\text { Компьютерный класс, современное } \\
\text { геодезическое оборудование, программное } \\
\text { обеспечение }\end{array}$ \\
\hline
\end{tabular}

В качестве примера РПД приведем аннотацию

одной из учебных дисциплин нового профиля:

Преподаватель: к.т.н., ст. преп. М. В. Цыдыпова

\section{Автоматизированные системы проектирования и кадастра ООПТ}

1.Место дисциплины (модуля) в структуре ОПОП. Дисциплина входит в вариативную часть блока Б1. Дисциплины (модули): Б1.В.02.04. К исходным требованиям, необходимым для изучения дисциплины относятся знания, умения и виды деятельности, сформированные в процессе изучения дисциплин из программы бакалавриата.

2. Цель освоения дисциплины: обеспечение будущих специалистов теоретическими знаниями и практическими навыками технологии сбора, систематизации, обработки и учета данных, применяемых в топографических, землеустроительных и кадастровых работах на компьютере.

3. Краткое содержание дисциплины. Производство топографогеодезических изысканий для целей землеустройства и кадастров. Тенденции развития геоинформационных, кадастровых систем и технологий, 
автоматизированных систем проектирования и область их применения в научно-исследовательской, проектной, производственно-технологической и организационно-управленческой деятельности; методики автоматизации проектных, кадастровых и других работ, связанных с землеустройством, кадастрами и градостроительной деятельностью; приемы и методы обработки геодезической информации для целей землеустройства и кадастров, управления, мониторинга и охраны земель заповедных территорий, методы получения, обработки и использования информации.

4. Компетенции, формируемые в результате освоения дисциплины:

- способность использовать современные достижения науки и передовых информационных технологий в научно-исследовательских работах (ПК-12)

5. Планируемые результаты обучения. В результате освоения дисциплины обучающийся должен:

\section{Знать:}

- методики землеустроительного и градостроительного проектирования, автоматизированной системы ведения кадастра недвижимости;

- тенденции развития геоинформационных, кадастровых систем и технологий, автоматизированных систем проектирования и область их применения в научно-исследовательской, проектной, производственнотехнологической и организационно-управленческой деятельности;

Уметь:

- использовать современные программные и технические средства информационных технологий для решения задач землеустройства и кадастров;

- проводить организационно-управленческие расчеты и техническое оснащение рабочих мест;

- выполнять ввод и редактирование картографической информации в ГИС; осуществлять актуализацию землеустроительных данных в базе данных ГИС;

\section{Владеть:}

- технологией сбора, систематизации и обработки информации, заполнения кадастровой документации, текстовых и графических материалов для целей землеустройства, кадастра и мониторинга земель;

- методикой автоматизации проектных, кадастровых и других работ, связанных с землеустройством, кадастрами и градостроительной деятельностью; 
- приемами и методами обработки геодезической информации для целей землеустройства и кадастров, мониторинга земель;

- навыками работы с современными системами управления баз данных;

\section{6. Общая трудоемкость дисциплины.}

5 зачетных единиц (180 часов).

\section{7. Форма контроля.}

Промежуточная аттестация - зачет (1 семестр), экзамен (2 семестр).

Заключение. Таким образом, разработан новый магистерский профиль по направлению обучения «Землеустройство и кадастры» на кафедре «Земельный кадастр землепользование» БГУ. Авторский коллектив уверен в востребованности данного профиля обучения для устойчивого развития Байкальского региона, а также считает его актуальным и для других субъектов Российской Федерации, т.к. он затрагивает общие вопросы заповедного дела страны. Полученные специальные знания позволят будущим магистрам решать спорные вопросы, связанные с землепользованием и землеустройством на ООПТ с учетом их категорий, управлением, экологическим планированием, контролем, мониторингом и охраной земель заповедных территорий.

\section{Список литературы}

1. Боголюбов С.А. Реализация экологической политики посредством права. Москва: Институт законодательства и сравнительного правоведения при Правительстве Российской Федерации: ИНФРА-М, 2015. 320 с. www.dx.doi.org/10.12737/13258.

2. Боголюбов С.А., Позднякова Е.А. Правовые основы природопользования и охраны окружающей среды. Москва: Юрайт, 2020. 429 c. URL: https://urait.ru/bcode/450366 (дата обращения: 11.08.2020).

3. Дудников В.Ю. Государственный кадастровый учёт участков в составе земель особо охраняемых территорий и объектов// Ресурсы Европейского Севера. Технологии и экономика освоения. 2015. N 1. С. 118-125.

4. Юрлова А.А., Литвиненко Н.В. Современная организация использования земель особо охраняемых природных территорий в системе природопользования // Вестник Государственного аграрного университета Северного Зауралья. 2016. N 4. С. 162-168.

5. Лунева Е.В. Правовой режим земельных участков в особо охраняемых природных территориях. Москва: Статут, 2018. 159 с.

6. Боголюбов С.А. Актуальные проблемы экологического права. Москва: Юрайт, 2016. 498 с. 
7. Карзенкова А.В. Право собственности на природные ресурсы // Вестник Пермского государственного гуманитарно-педагогического университета. Серия N 3. Гуманитарные и общественные науки. Пермь, 2017. С. 128-145.

8. Русецкая Г.Д., Дмытерко Е.А. Особо охраняемые природные территории - инструмент устойчивого управления природопользованием // Известия Байкальского государственного университета. 2017. Т. 27, N 4. C. 478-487. DOI 10.17150/2500-2759.2017.27(4).478-487

9. Yelayev E.N., Gomboyev B.O., Batorova G.N. The master's program of ecology and nature management in the Buryat State University as a member of the network of the University of the Arctic («The Middle of the North: the conservation of biodiversity and sustainable development») // Arctic dialogue in the global World: International scientific conference (16-17 June 2015, Ulan-Ude, Russia). Ulan-Ude: BSU Press, 2015.

10. Хертуев В.Н., Дмитриева А.В., Григорьева Л.О. Становление и развитие направления "Землеустройство и кадастры" БГУ // Землеустройство, кадастр недвижимости и мониторинг земельных ресурсов. 2018. С. 6-12.

11. Антипов А.Н., Калихман Т.П. Менеджмент охраняемых природных территорий на объекте всемирного природного наследия «Озеро Байкал». Иркутск: Институт географии СО РАН, 2005. 21 с.

12. Елаев Э.Н., Елаева Н.Г. ООПТ Байкальской природной территории: история становления, проблемы и перспективы развития // Образование и наука в Байкальской Азии: сборник научных трудов к 80-летнему юбилею БГПИ-БГУ. Улан-Удэ: Изд-во БГУ, 2012. С. 195-201.

13. Елаев Э.Н. Ландшафтно-экологическое зонирование особо охраняемых природных территорий Байкальской Сибири // Природа Внутренней Азии. № 3 (8). 2018. C. 84-91. DOI 10.18101/2542-0623-2018-3-84-91

14. Панкова Т.О., Дмитриева А.В. Особо охраняемые природные территории Бурятии // Земля-развитие-2019. С. 219-223

Tsydypova M.V., Radnaeva O.N., Khaltayeva A.G., Sushkin K.A., KhertuevV.N. Creation of map of elements of the habitat of hunting resources of the state national biological reserve «Snezhinsky» based on remote sensing data and GIS technologies // Proceedings of the V International scientific and practical seminar «Modern technologies in protected natural territories activity: Geoinformation systems, Remote sensing of the Earth».Minsk, 2019. P.93-95.

(С) Э.Н. Елаев, В.Н. Хертуев, А.В. Дмитриева, М.В. Цыдыпова, 2020 